\title{
Insight Into Special Education Teachers' Practices With Preschool Children in Saudi Arabia
}

\author{
Faris H. Algahtani ${ }^{1}$ \\ ${ }^{1}$ Department of Special Education, Faculty of Education, University of Jeddah, Saudi Arabia \\ Correspondence: Faris Algahtani, Department of Special Education, Faculty of Education, University of Jeddah, \\ Saudi Arabia. E-mail: fhalqahtani@uj.edu.sa
}

Received: April 23, 2018 Accepted: May 27, 2018 Online Published: June 11, 2018

doi:10.5539/gjhs.v10n7p73 URL: https://doi.org/10.5539/gjhs.v10n7p73

\begin{abstract}
Special educational teachers' practices in a centre for children with intellectual disabilities in Saudi Arabia were shown to be influenced by the Islamic and Arab context together with differing understandings of disability and American-influenced treatments of what are seen as inappropriate behaviours. Knowledge of the interventions which teachers find useful and effective enables identification of potential improvements in educational services for preschool children. In this interpretive qualitative study, data were collected from semi-structured interviews with fifteen teachers in a single centre. Findings identified through thematic analysis of the data are presented in three main categories: play as intervention, structure, and behaviour improvement. Teachers emphasized the importance of correcting behaviour as a prerequisite for more academic learning, with some acknowledgement of a child's need for freedom and growing interest in Montessori. Key issues of initial teacher training and professional development would be addressed by the adoption of a more child-centred approach may be more suited to an Islamic approach to childhood.
\end{abstract}

Keywords: intellectual disabilities, Islam, preschool, special education

\section{Introduction and Context}

Disabilities are conceptualized differently in different countries and cultures, and Saudi Arabia has used a definition, criteria and classification of intellectual disabilities (ID) based on The American Association of Intellectual and Developmental Disabilities (Richards, 2014). The criteria were IQ level, adaptive behaviour, and manifestation under the age of 18. Mild intellectual disabilities (MID) were associated with IQ scores from approximately 50 to 75, taking account of the other criteria (Schalock et al., 2010). Although the term 'developmental delay' is typically used with reference to children under five because results of testing are less reliable (Shevell, 2008), Saudi Arabia uses ID for all preschool children as the group includes five to six year olds who can be appropriately assessed before entering primary school.

Early Childhood Intervention (ECI) services and preschool provision for children with ID are expanding rapidly through a network of Intellectual Disability Centres (IDCs). Importance is attached to ECI in helping to reduce the effect of impairments through tailored support (Almalki, 2013; Goddard, Davidson, Daly, \& Mackey, 2008). Initial assessment identifies developmental delays or disabilities by evaluating cognitive, health and social developmental dimensions. An early start enables children to gain as many skills as possible in the early years (Almalki, 2013).

The effectiveness and quality of interventions depend on factors which include assessment (Guralnick, 2011), appropriate training and development for special education teachers (Almalki, 2013; World Health Organization [WHO], 2012), and collaboration among professionals (Chen, Klein, \& Minor, 2009). Higher quality preschool provision is associated with higher attainment in mathematics and reading in the first primary school year (Sammons et al., 2003).

Over the next 5 to 10 years, it is vital to ensure that special education teachers (SETs) in IDCs have the professional development they need to provide quality learning experiences to preschool children with intellectual disabilities. The starting point and research question was to understand which interventions and methods preschool SETs employed and which they perceived as most effective in terms of providing the greatest possible benefits for the children. 
It is essential to understand the country context, the role of education, the conceptualisation of disability and special educational needs, and the approach to child development. Every aspect of education is shaped by Islam and by the meaning of the Arabic word for 'education'. The latter encompasses guiding people to maturity, and acceptance and performance of social and moral rules, as well as gaining knowledge (Al-Attas, 1979; Risha, 2014). The objectives of education include: to understand Islam correctly and completely, to provide pupils with Islamic values and precepts, to gain knowledge and skills, to acquire constructive behavioural tendencies, and to enable pupils to play a helpful role in building their society (Ministry of Education, 1976). Pupils should achieve their full potential while conforming to Islamic teachings and the values of Saudi society (Education Policy Articles 2-5, Ministry of Education, 1976).

Religion and Saudi Arab culture both value a conformist, conservative approach to society, with important differences. Whereas an Islamic approach values individuals and their differences as creations of Allah, traditional Arab culture tends to stigmatise disability. This is reflected in underlying tensions between a child-centred approach to development and a model of disability which seeks to remedy defects and normalise the child to fit into society.

Saudi Arabia supports the integration of pupils who have disabilities with their peers in the Least Restrictive Environment (LRE), based on the United States' Individuals with Disabilities Education Act (2004). The nature and severity of disability determines the educational setting, curriculum and extent of social interaction with children who are non-disabled, although supplementary aids and services are employed to enable the achievement of full potential in terms of meeting educational objectives in a regular education setting (Al-Ahmadi, 2009). The aim is for pupils to gain equal access to education rather than to give them the sense that they belong in a mainstream environment and have a right to be completely involved at all times, as with true inclusive education (AlShahrani, 2014). Although in 2000, legislation granted children aged from four to six and assessed as having intellectual disabilities the right to access the same preschools as their normally developing peers (Alajmi, 2006), children may not always have access to a suitable school due to insufficient places.

Generic programmes and plans for children with intellectual disabilities have been developed by the Directorate General of Special Education (Ministry of Education, 2012). The Directorate supports SETs through oversight of their initial teacher training and provision of in-service workshops and seminars (Hegarty, 1995). Initial teacher training emphasizes theoretical knowledge of medical conditions and a limited range of specific teaching and behaviour modification strategies to be applied in special education programmes. Detailed procedures are specified in the Rules and Regulations of Special Education Programmes (Ministry of Education, 2001), adapted from United States legislation. These regulations stipulate adequate training for SETs, assessment procedures for determining needs, and implementation of individual education programmes for children who are eligible, in addition to describing how children with disabilities can benefit from early intervention programmes (Alquraini, 2011).

Help from ECI services typically begins either when parents suspect a problem with their child's development and take the child to an ECI centre or a hospital for assessment, or when medical staff diagnose a disorder associated with disability, such as cerebral palsy, and follow Ministry of Health procedures.

There is increasing divergence of mainstream and special education provision for preschool children with ID. Mainstream preschools use a curriculum which emphasises flexibility, freedom, play, interaction, appreciation and respect of children's culture and identity, together with knowledge, skills, and constructive relationships between preschool and families (Samadi \& Marwa, 2006). Child-initiated activities are moderated by greater stress on the role of the adult in Islam directing the child's learning and development, and promoting appropriate behaviours (Samadi \& Marwa, 2006). Comprehensive nationwide preschool provision is planned, based on the adaptation of western child-centred approaches in which children are considered active learners (Al-Othman, Gregory, Jesse, \& Khalil, 2015).

Meanwhile, preschool special education in IDCs continues to emphasize the importance of SETs' knowledge of behaviour modification to achieve better control of behaviours and improve pupils' adaptation (Abdel Aziz \& Alzarea, 2013). This could make it more difficult for SETs to maximise a child's chances of progressing to an inclusive mainstream school where attainment standards are expected to be higher in the future.

The model of SEN and disability in Saudi Arabia can be described as containing elements of the deficit model, the social model, and the human rights model (Frederickson \& Cline, 2009), combined with elements from Islam. In Islam, whilst every individual has absolute equality in the sense that each one was created by Allah (Hassanein, 2015), it is accepted that individuals have particular strengths and weaknesses. Islam instructs people to help each other for the benefit of everyone, for example those with health and wealth are instructed to take care of the infirm 
and poor. The relationship is based on a shared love of Allah and mutual dependence and help among people, in contrast to the value attached to greater independence in Western societies. Diagnosis and categorisation of disabilities is the starting point for identifying the help required and who is best placed to provide it.

The deficit model is consistent with the strong and enduring value of conformity derived from the Bedouin culture (Patai, 2002). Development is measured against norms for age-matched peers, and causes are sought for deficits so that possible remedies can be identified (Macdonald, 2009). One important drawback of this model is that it concentrates on what the child cannot do, focusing on the disability rather than the child.

In Islam, parents must take especial care of their children so that they can participate well in everyday life situations (Cairo Declaration on Human Rights in Islam, 1990). Children with ID should be given greater help to achieve their potential in keeping with the duties required of every Muslim to better understand and obey Islam through seeking knowledge. Article 9-a in the Cairo Declaration on Human Rights in Islam (1990) affirms that the state and society have a duty to provide educational services which can be accessed by all individuals. The roles of the individual, parents and other family members, health and education professionals, and the state are clear. Whilst this resembles the social model of disability, changes taking place in Saudi Arabian society which enable children with disabilities to participate more fully, such as the spread of inclusive education, occur because they are consistent with the teachings of the Qur'an.

The human rights model strongly opposes segregated education and requires rights to be enshrined in law. It assumes that every individual with a disability has a right to participate fully in the economic, political and social life of their society. For children, this implies 'special rights to education' rather than special needs, which involves a complete rethinking of educational provision. Children with ID in Saudi Arabia have the right to an education but not 'special rights'.

Implementation of appropriate preschool provision is beset by difficulties, which include the scale of the problem, competition for resources to meet multiple challenges, the co-existence of Islamic and pre-Islamic Arab cultures, and tensions arising from adapting Western approaches. It is not surprising that medical model elements dominate, because assessment, diagnosis and treatment offer an obvious way for people with advantages in life to help those at a disadvantage.

The extent to which the Islamic model is compatible with various child development theoretical frameworks requires the acknowledgement of deep cultural differences. The Western concept of individual happiness and freedom contrasts sharply with the Islamic concept of happiness which is based on being a true believer and doing good, with equal importance attached to happiness in earthly and everlasting life (Jafari, 1992). The predominant child development framework in Saudi Arabia rests on the principles of human development found in the Qur'an. These principles can be summarised as growth and development occurring in a gradual process which follows a set sequence of stages within an overall pattern of life. The importance of good environmental influences and adult guidance, combined with the avoidance of bad influences, is stressed in all the teachings of Islam. Parents are responsible for ensuring their children are aligned to God from the day they see the world. Parents have a right to obedience from their children, who have an obligation to be obedient.

Piaget's theory is taught briefly in Initial Teacher Education for SETs but has not been widely applied (Al-Abdulkareem \& Hentschke, 2014). Although preschool teachers have good knowledge of Piaget and constructivist theories in general, they tend in practice to adopt the methods of experienced teachers and incorporate the elements of theory which fit with the prevailing traditional culture (Al-Jadidi, 2012).

Psychoanalytic theories are rejected because they assume development is driven by a sequence of innate urges that are totally separate from religion (Open University, Department for Children, Schools and Families, Royal Holloway University of London, \& NSPCC, 2007). Behaviourist or social learning theorists like Bandura are more congruent with the Islamic worldview, since both propose interaction of the individual, environment and behaviour (e.g. Bandura, 1977). Behaviour is learned through modelling, thus the behaviours of parents and other adults are important influences on the child's development. Developmental models can be criticized as giving too much emphasis to who the child will become in the future, and too little to who the child is at a particular moment in time. Professionals may need to recognise when it is appropriate to focus on the present rather than the behaviours, knowledge and skills needed for the future.

Bowlby's attachment theory asserts the necessity of a protective figure when environmental threats are presented (Bowlby, 1982). In Islam, the lifelong attachment is to Allah and there is no separation even in death. Language used by Bowlby to describe the attachment figure, such as loving, comforting and available, is used in Islam to describe Allah. Parents or guardians are the mechanism through which the attachment is achieved. This is taken 
into consideration in the design and delivery of all educational provision in Saudi Arabia including Early Childhood Intervention.

The ecological theory proposes various levels of environmental factors that interact with the child (Bronfenbrenner, 1979). In this theory, God is a feature of the outermost level of influence and contained in the broad ideology, customs and laws of the culture. Although this recognises that societies like the US and UK contain different cultures with widely differing family traditions and various religious beliefs, it conflicts with the unifying nature of Islamic society, so is largely rejected.

However, child development research concurs with the Qur'an that the rate of development and learning is most rapid in the preschool stages. It is essential to take advantage of these stages and what are termed the most teachable moments (Yadav, 2016), because the child may find it more difficult to learn a particular skill later on (WHO, 2007). This places considerable responsibility on the SETs who deliver services for preschool age children with ID.

\section{Literature Review}

Internationally, reviews of interventions and meta-analyses of research have revealed shared themes: interactive approaches based on play and interaction with key adults and peers; approaches to communication; integration approaches which include behaviour, natural learning environments and Applied Behaviour Analysis (ABA); structured teaching; and acquisition of daily life skills (e.g. Jordan, Jones, \& Murray, 1998; Räty, Kontu, \& Pirttimaa, 2016). Play is important in the early years, motivating and supporting children with ID to acquire new skills and concepts, language and communication, concentration and a positive attitude towards engaging with others (Siraj-Blatchford \& Clarke, 2001). Children with ID are considered to benefit from play with a few simple rules (Saracho, 2012). Purposeful structured play is considered vital for early development, whereas extended free play has been shown to be ineffective in promoting development (McLachlan, Gilfillan, \& Gordon, 2013). Teachers need to be clear about the objectives of play, because developing play skills and using play to develop other skills demands different purposes and approaches; meeting the child's needs through play is facilitated by clear strategies (Lifter, Foster-Sanda, Arzamarski, Briesch, \& McClure, 2011).

Children with ID and limited verbal skills can benefit from augmentative and alternative communication interventions (AAC) (Wilkinson \& Hennig, 2007), such as manual signs and gestures (National Research Council, 2000; Schlosser \& Wendt, 2008). Visual cues assist children to move from one activity to the next, something they otherwise often find difficult (Heflin \& Simpson, 1998; Schopler, Mesibov, \& Hearsey, 1995). Frost and Bondy (2002) and Schlosser and Wendt (2008) report research findings which support the use of the Picture Exchange Communication System (PECS). Key influences on outcomes include sufficient teacher training in the utilisation of AAC to support a child's use of the systems and subsequent development (Barker, Akaba, Brady, \& Thiemann-Bourque, 2013; Howlin, Gordon, Pasco, Wade, \& Charman, 2007) and parental involvement in using AAC (Kaiser \& Roberts, 2013).

Integration approaches which include behavioural techniques have seen a shift towards detecting antecedents and development of alternative responses to events and to positive reinforcement rather than punishment (Meyer \& Evans, 2006). ABA is not an essential element in an IDC programme (Lovaas, 1987) but can be a valuable intervention for children with ID who have limited imitation and verbal skills (Smith, 2001). Social Stories have grown in popularity as a means of helping children to realise what they need to do and what is considered suitable behaviour in various social situations (Machalicek et al., 2008).

Structured teaching as exemplified in TEACCH (Treatment and Education of Autistic and Communication related handicapped CHildren) requires structure at every level from the learning environment through schedules and routines to the visual structuring of tasks and the materials used. Evaluation studies have indicated that the TEACCH programme can result in some preschool children with severe ID and autism making noteworthy progress in several developmental domains together with improvements in behaviours (e.g. Panerai, Ferrante, \& Zingale, 2002). One study reported a statistically significant increase in children's expressive and receptive language skills, and a corresponding reduction in parental stress, with a TEACCH-based Early Intervention Programme enabling parents to utilise the techniques at home (Braiden et al., 2012). However, a 2013 meta-analysis of 13 studies proposed that effects probably vary by domain, with small effects for cognitive, communication, daily living motor, perceptual, and verbal skills, in contrast to moderate to large effects on maladaptive and social behaviours (Virues-Ortega, Julio, \& Pastor-Barriuso, 2013).

However, children should not rely too much on adults and other types of intervention may be needed to enable greater independence and generalisation in the use of the skills to new settings (Denning \& Stanton-Chapman, 
2014; Rogers, 2000). Whereas adult-mediated interventions usually request a certain pattern of behaviour, naturalistic interactions are learned from peers without previous planning (Goldstein, Schneider, \& Thiemann, 2007). Children have been shown to learn social interactions more effectively in more naturally occurring situations involving peers than in adult-mediated interventions (Goldstein et al., 2007).

\section{Methodology}

This study adopted a qualitative interpretive approach in order to gain a detailed understanding of how special education teachers in an IDC operate in the classroom. The interpretive approach ensured that the researcher's positionality and views were considered reflectively and distinguished from participant responses, thus enabling participants' voices to be clearly heard. Ethical approval was granted by the appropriate research committee. Fifteen semi-structured interviews were conducted in Arabic with experienced and qualified teachers to collect examples of interventions they considered effected. Transcripts were translated by the bilingual researcher in order to capture the meanings and culture, in accordance with Birbili (2000) and Shklarov (2007). Participant quotes were therefore translated as literally as possible. Data were analysed using thematic analysis, based on themes identified from the literature together with new themes emerging from the data.

\section{Findings}

Bearing in mind that 'educational interventions' in Saudi Arabia include behavioural and social skills interventions which assist pupils to live according to Islamic rules and values, it is not surprising that SET responses related strongly to the development of those skills alongside communication skills. SETs considered these to be the necessary first steps before more academic skills were attempted. It was felt vital to assist children to develop the communication skills needed for everyday life and for interacting with teachers and peers in a mainstream primary school or special education institute.

Findings are presented in three broad categories encompassing the practices, interventions and teaching methods considered positive and effective for preschool children with intellectual disabilities: play as intervention; structure; and behaviour improvement. SETs utilised a diversity of techniques in a process of intensive intervention according to the skills targeted and the needs of the individual child. They aimed to provide a combination of dynamic and engaging activities throughout the teaching day. Table 1 summarises the main practices, interventions, and skills targeted.

Table 1. Effective practices, intervention techniques and targeted skills improvement

\begin{tabular}{|c|c|c|}
\hline $\begin{array}{l}\text { Group } \\
\text { no. }\end{array}$ & Teaching intervention, method, technique & Targeted skills improvement \\
\hline 1 & Play as intervention & $\begin{array}{l}\text { reciprocal social interaction; social skills; simple play skills; } \\
\text { more complex levels of play; language; communication }\end{array}$ \\
\hline \multirow{5}{*}{2} & $\begin{array}{l}\text { Structure in all activities and the learning } \\
\text { environment }\end{array}$ & social and communication skills; \\
\hline & Structured teaching $(\mathrm{TEACCH})$ & making transitions \\
\hline & $\begin{array}{l}\text { Communication using signs, gestures and } \\
\text { pictures (PECS, schedules with pictures) }\end{array}$ & $\begin{array}{l}\text { communication skills; making transitions; making choices; } \\
\text { self-organisation }\end{array}$ \\
\hline & Adult-led interventions & social and communication skills, greater awareness of social \\
\hline & Social education stories & cues, social skills \\
\hline \multirow{9}{*}{3} & \multirow{9}{*}{$\begin{array}{l}\text { Behaviour improvement } \\
\text { Adult-led interventions } \\
\text { Applied Behaviour Analysis } \\
\text { Sensory and motor/visual motor interventions } \\
\text { Functional approach to problem behaviours }\end{array}$} & suitable social behaviours; \\
\hline & & $\begin{array}{l}\text { interaction for children with limited verbal abilities; imitation } \\
\text { skills; joint attention skills }\end{array}$ \\
\hline & & reduce atvnical sensorv resnonses. \\
\hline & & . \\
\hline & & $\begin{array}{l}\text { 1ncrease quietness and tocus; tine motor coordination; motor } \\
\text { skills; }\end{array}$ \\
\hline & & adaptive skills e.g. tying shoelaces \\
\hline & & reduce unwanted behaviours \\
\hline & & teach new behaviours \\
\hline & & strengthen goal behaviours \\
\hline
\end{tabular}




\subsection{Play as Interventions}

All participants endorsed the effectiveness of using play to encourage communication and social skills. They found that play was most effective when it was structured, physical and interactive, noting that other activities within a highly structured day needed to include elements of play. Computer technology was seen to benefit some children who preferred solitary play because it offered interaction, colour and varied activities. Selected quotes from SETs illustrate that play was used to develop play, verbal and social skills, communication and interaction:

"Play can benefit many areas of development in multiple settings, whether in the classroom or at home...so helps the child to use language, movement, releases energy and communicate with peers and adults" (SE2).

"Sometimes, we have a 20-25-minute play session. During that time the children play with toys while the SET models, facilitates and instructs the children on particular play behaviours to induce the child towards a more complex level of play... questions and comments encourage the child to use language, [and help to] develop thinking and reinforce verbal interaction" (SE4).

The emphasis on using play to develop social and communication skills is consistent with the importance attached to these skills as a vital component of education in a conformist, Islamic society.

\subsection{Structure}

A second major theme was structure throughout all activities and the learning environment, including the physical setting, schedules, visual signs and strategies, and tasks:

"Structure is fundamental, what I keep referring to as the life and death of a situation. I think that is fundamental" (SE2)

"A structured learning environment especially in the schoolroom gives the child individualized, structured teaching and assists the child to practise, promote independence and engage with peers interactively" (SE7).

"If something should occur and it does not occur, then it will generally trigger an emotional upset. So that is why we have a considerable measure of structure, just due to that fact. For example, we have chocolate every morning" (SE13).

The experiences of SETs trained in TEACCH led them to conclude that the approach benefited preschool children with communication disorders. Structure was the foundation of behaviour improvement and learning. TEACCH techniques were matched to achieving targets set in Behaviour Improvement Plans (BIPs). A focus on establishing an appropriate learning environment with the use of clear and concrete visual information, accompanied by activity schedules with photo symbols, assisted children to visualise their daily routine and 'what comes next'. Cards depicting activities were changed as children moved between activities. Some SETs produced scheduled activities for children to use at home, which some parents had said helped greatly in managing their children's behaviour.

“One father said 'my son used to have two different behaviours at home and at school)'... I created scheduled activities for his daily routine in terms of picture cards to use at home. These picture cards include examples such as 'put on your pyjamas, put your stuff in your box, teeth brushing time and bedtime.' He finds that if his son can see what is coming next, he is good with his routine, no major bad behaviours or anything" (SE7).

TEACCH can lead to progress which teachers and parents can see. This motivates SETs and provides satisfaction for parents. Children in Saudi Arabia may have a greater feeling of belonging if they are perceived and treated as relatively 'normal' by their family and the wider highly conformist society.

One frequently used TEACCH strategy was a 'work first, then play' structure of learning tasks that had a positive practical effect on a child's life. Red circles with pictures underneath represented two tasks to be completed before a reward of fun time (green circle) was gained. This strategy was later extended to three or four 'work' circles before a 'play' circle was earned, and, for children who could read, tasks and rewards were written on the board. This technique was considered an easy way of increasing self-direction in learning.

Structuring activities and tasks occurred at a level of fine detail, as illustrated by the following example:

"Before the end of playtime, [we need to] help children to be prepared for the end of playtime, so we gain the children's attention, let them know we are setting the timer [signalling the end of breaktime] for 1 minute. Then [we tell them to] sit down in the corner of the hall, have a drink of water, and then tell them it is time to go back to their classrooms when the timer sounds" (SE5).

Structured teaching and tasks were complemented by small group activities, with a class divided into two or three groups to enable SETs to more easily provide support for the development of social and communication skills. 
Illustrative quotes are:

"In a small group activity, we do many activities such as singing, listening to stories or to the holy Qur'an. We sometimes do painting, colouring or watch videos. We also teach children how to engage in an activity and learn social skills in the context of tasks that attract their attention. It is easy for me to control the classroom" (SE14).

"A small group activity is one of the practices that I do every day. It takes about 15 to 20 minutes. All the children sit and do simple games or simple craft. A small group can promote listening skills, social skills, and physical tasks that assist the children to reduce problems and be disciplined" (SE15).

Small group times are a critical component of a preschool day, contributing to a consistent routine and engaging all children in an activity that leads them to learn better (Wasik, 2008; Worthington, 2008). Small groups are less overwhelming and the teacher can give more attention to specific points.

Participants continually stressed the importance of communication, highlighting that straightforward manual communication and signs allowed them to cut through the complexities of spoken language. SETs also used signs and gestures as components of a wider communication process with children who were able to communicate verbally. Some children chose to continue using manual signs in interactions with other children after acquiring language:

"One child who learned to utilise manual signs in the IDC programme for simple objects such as "drink", "eat," "play," and "sit", even after she gained some language, $\mathrm{H}$ still used signs to communicate with nonverbal peers in the IDC. H's mother felt this facilitated H's social interaction with peers at the IDC and at home" (SE9).

One specific method of AAC which was widely used in the centre was the Picture Exchange Communication System (PECS), a structured system based on the exchange of picture codes. Participants had generally favourable perceptions of the use and outcomes of PECS. The centre's stock of materials (board and picture cards, in black and white, and colour) was used by SETs who had attended a basic coaching workshop and followed the coaching manual step by step. These SETs were positive about utilising PECS as one of many methods, especially with preschool children with ID who were still developing speech. Some reservations were expressed about its wider benefits; some children had not used it despite completing almost all the levels, while others had continued with it beyond the point where teachers considered it useful (SE3). Some participants encouraged the use of PECS at home by working with the Speech Therapist to make PECS notebooks for parents and children. PECS was found to be especially efficient in encouraging and improving communication skills when it was combined with speech language therapy (SE4 and SE9).

Illustrative quotes showing SETs' pleasure at progress made with PECS are:

"When I worked with one little girl, she got her Picture Exchange Communication System notebook and took it to another SET and told her what she needed, which was gorgeous. She knew where it was, and she knew what was in it, and she made her understand 'I want this' and the SET brought it to her" (SE10).

"We made a copy of Picture Exchange Communication System for one parent to use at home. The mother said her child did just fantastically with it. He had pictures for TV, iPad, playground, games, sleep, drawing, eating and toilet. Then his language improved wonderfully, [so] he no longer needed to use them. However, it was useful in the early years" (SE12).

Adult-led interventions were perceived as effective in facilitating the development of communication and social skills. SETs stressed the importance of these interventions in helping to fulfil the duty of guidance placed upon Islamic parents and other adults to ensure children have a good Muslim upbringing until the age of 14 (Al-Azhar University \& UNICEF, 2005). SETs reported that using adult-modelling, role play, and priming in combination with peer-modelling was efficient in classroom settings. They provided guidance to peers during interactions with children with ID, then included an intervention by an adult to enhance and reinforce the peer guidance.

Capturing the child's interest and providing plenty of opportunities to practise new language and skills were highlighted as important factors in using these approaches effectively.

\subsection{Behaviour Improvement}

More than half the participants found that social educational stories offered a simple, engaging and effective way of teaching social skills and increasing awareness of social cues. Some SETs supplemented existing resources with stories they wrote to suit a particular group of children and the Islamic context. For example:

"I have written many little stories, about things like asking for help, wearing your clothes, or keeping them on, keeping hands to yourself, break time activities, building friendships, tasting new foods, what to do when an adult 
talk, and how to greet someone. Keeping your clothes clean, what to do at the weekend, how to pray, how to be a good friend, what to do when your mum is talking..." (SE9).

The use of social educational stories to convey the views of others and suggest ways of implementing suitable social skills accords with the literature (Gray, 2000; Machalicek et al., 2008). Some SETs shared stories with colleagues and with parents. This sharing of good practice could be used to great effect with many interventions.

The third major group of interventions addressed behaviour improvement, using a combination of adult-led interventions, ABA, sensory and motor interventions, and a functional approach to problem behaviours. Adult-led interventions included the use of PECS to teach behavioural rules to children who struggled to express their very basic needs and wants. Priming, adult modelling and role-play were considered appropriate for tackling behavioural issues. SETs suggested that feedback about inappropriate behaviour should include encouraging the child to think about different ways of responding and discussing possible reactions to the choices before replaying the incident as a role play while trying a different approach, "the rewind technique" (SE2). Modelling was described as the concept of habit-formation to improve behaviours (SE6) based on "teacher redirection" (SE5). It was seen to maximise opportunities for practising and experiencing exemplary social interaction in the natural environment. Exploiting naturally occurring opportunities assisted children to move from a learning situation to a practical application:

"In our daily routine in the IDC classroom I do a lot of verbal prompting to encourage our children to imitate correctly, with social skills... I will say 'what do you want to do?' or 'why not ask her and see if she will give you a doll or toy?' I may prompt them to give an alternative thing... For instance, I had a bag out and a child wanted another kid's bag. Then she went to get a different bag to give to the other child" (SE3).

The 'rewind' often dealt with inappropriate behaviour, as in the following example:

"Yesterday, I had a child just jump up out of his chair, out of his desk... he was upset when another child commented on his actions and pushed the chair he was sitting on and he made some angry noise. Then I told her 'all right, let's see what occurred from the beginning, step by step. Explain what happened. Say that once more. Can you make a different choice?"' (SE2).

Another approach was ABA with discrete training. This was used more by SETs working with nonverbal young children who had severe intellectual disabilities, typically in one-to-one instruction with reinforcers for the development of engagement and imitation skills as essentials for future learning. Regular use of ABA was limited to around 30 minutes a day for children who benefited from this method. The application of ABA for children deemed to benefit from it is consistent with the emphasis on correct behaviour in Islamic teachings and parenting:

"The goal of using ABA is to analyse and change behaviour to be more reasonable and to reduce undesirable behaviour. I found the ABA model works well in changing behaviours such as excessive anger, aggression and hyperactivity" (SE4).

SETs varied the reinforcer to suit the child and the moment: time away, tickling, glitter visuals, a card to exchange in the canteen, stickers, candy, free time on the computer, and juice drinks, among others. Their use of ABA is consistent with the recommendations of Lovaas, 1987 and Smith, 2001.

Sensory and motor interventions were utilised to reduce atypical sensory responses, help children to become calmer, and develop coordination and fine motor skills. SETs highlighted the effectiveness of brushing, deep pressure, movement, and toys for calming senses or engaging attention, in addition to occupational therapy. Benefits were reported to vary with the type of sensory motor intervention and therapy, as well as with the age of the child. One special education teacher (SE11) was a strong advocate for sensory motor intervention, sensory toys, exercise and movement. Searching with hands for small plastic objects in sand, shaving cream and other textures helped to reduce tactile hypersensitivities, while sensory toys helped to lower auditory and verbal sensitivities. Other SETs took advantage of the occupational therapy (OT) room for sensory breaks, movement, and exercise.

The following quotes illustrate SETs understanding of a child's enjoyment of mess as well as order, and the need for freedom:

"Today we are finger painting with white shaving foam or cream of some kind. Once a week, particularly on Mondays, we do the sensory desk and play dough. Last Monday, we placed silver coins (half riyal) on the sensory desk in the sand...We put a black pen in the grass on the sensory desk. It was all over the place...a very big mess. We can change what we want - such as salt, rice or water - to assist the children to know the materials and touch them. Children love that" (SE11).

"At times they tend to need to have soft things on them, or they simply need to be free of things that are binding 
them. So that's when you want to take them into the Occupational Therapy hall and do a lot of bouncing on the ball, pressures and effort, letting them creep through the small tunnel in the hall, so when it's not being utilized by specialists, I take them in for say 20 minutes just to get the wiggles out" (SE5).

A systematic review of 27 studies indicated that sensory integration interventions could improve reading-related, active play and socialisation skills, as well as behaviours and sensorimotor skills (May-Benson \& Koomar, 2010).

The focus on interventions aimed at correcting behaviour continued with SETs' emphatic endorsement of a functional approach to problem behaviours. which they stated was highly efficient in diminishing, eliminating, and proactively avoiding challenging behaviours for preschool children with ID. Two positive behavioural methodologies were highlighted: antecedent interventions that concentrate on identifying the triggers that make problem behaviours more likely and adjusting the environment to minimize triggers, and interventions utilizing positive reinforcement to strengthen and increment goal behaviours while diminishing problem behaviours.

Illustrative quotes show the importance attached to identifying triggers:

"When we talk about the reduction of unacceptable behaviour with children with ID, according to my experience I believe the only thing you actually need to find out is, can you find a trigger for what gives rise to that? Antecedents is the right word and right way.... absolutely, discovering the antecedents, that's what I believe" (SE14).

"Withdrawing these children with intellectual disabilities out into little breakfast groups if at all possible instead of having to tolerate that big, noisy canteen all the time, has been efficient in eliminating sensory overload" (SE13).

Considerable use was made of an 'if / then' behavioural contingency to improve discipline generally, reinforce work implementation and decrease problem behaviours in specific instances, by pointing out that a particular behaviour may be followed by particular consequences (SE9). To help the child understand the reasons behind a short 'time out' following serious problem behaviours such as biting or hitting, the SET showed two pictures demonstrating the 'if / then' contingency. In general, SETs observed their approach to dealing with challenging behaviours to be more effective when they combined antecedent-based interventions, positive behaviour supports and positive reinforcements, with the aim of anticipating and preventing the behaviours. They believed that an early start and ongoing maintenance of these interventions was necessary to ease issues of transition as children progressed to higher classes.

These techniques are supported in the literature. Zanolli, Daggett and Adams (1996) assert that giving children cues, prompts and the chance to practise a target behaviour just before that behaviour has to be used, for example in a role play, have added benefit when combined with praise and reinforcement of appropriate reactions. Good behaviour is highly valued in children in Islam (Al-Azhar University \& UNICEF, 2005), as also seen in Islamic schools in Europe (Aslan, 2011; Scourfield, Gilliat-Ray, Khan, \& Otri, 2013). This largely explains participants' emphasis on interventions targeting behaviour improvement.

\subsection{An Alternative View}

In contrast to these interventions, one SET with a passionate interest in the field of disability had translated the book 'Montessori from the Start' into Arabic, enabling others to access the principles and ideas when accredited courses were not available. SETs recognised that they were using a selection of simplified elements of the Montessori method that corresponded to daily living goals in children's Individual Educational Plans but were strongly attracted to the more child-centred Montessori philosophy. One important difference between Montessori and other structured approaches is that no extrinsic rewards are given; instead, learning and the enjoyment of learning provide intrinsic rewards.

"Some activities help children in their task of self-formation. The Montessori technique of self-discovery and hands-on learning are suitable and practical guides to raise calm, confident and competent children" (SE10).

Five SETs saw strong similarities between elements of Montessori and their own teaching regarding the "focus on daily life activities, the concentration on senses" (SE10). One emphasized that senses were the basis of developing thinking; "at this age, the children can build themselves through thinking and discrimination" (SE10). Another reported how guided learning in the spirit of the Montessori Method gives a child time to explore and play freely:

"If the children show some sort of interest in colours, we try to refine their awareness of colour and understanding of colours in the environment. We use three primary colour boxes, yellow, blue, and red. The children try holding the box, taking the colour tablets out of the box, matching them, and naming them. Trying to match colours in the environment... in this task the child tends to explore, take his time, and play freely; whether alone, with children or with the SET. In this way, the child takes time to work, feels free... no one is directing him" (SE15). 
SETs favouring the Montessori philosophy emphasized the need for children to have freedom in their development:

"During the activities each child has freedom to sit anywhere they like and they can move around as they like, there are no restrictions. They also have the opportunity to choose an activity with unrestricted time to do the task. In this case, the teacher provides the child with the opportunity and environment to foster reliance on himself/herself without any direct intervention" (SE10).

"In my view, when children are free, they acquire new skills to act independently - we are observers, looking to see if the child needs any help" (SE12).

However, considerable differences existed between Montessori's concept of 'freedom' and practices in the IDC. The lesson divisions and activities were the teacher's choice rather than the choices of individual children, and the overall timing was broadly allocated by the centre co-ordinator in a far more restrictive way than the plan of a typical day in a Montessori school.

"Training the children to rely on themselves through several activities ... for example, I divided the class into some parts: 1. practical life activities: Opening and closing different types of doors, cupboards and cabinets. Other activities could include pouring water into a cup, taking a chair from under the table and lifting it and carrying it away and back again to its place under the table .... 2. Sensorial part. 3. Language part. 4. On self-reliance, such as washing hands and face, brushing hair and hanging clothes on the hanger. Carefully going upstairs and downstairs" (SE10)

One study reported that Montessori children were better able to adapt to change as measured by an exercise with changes of instruction in how to sort cards (Lillard \& Else-Quest, 2006). In other studies, teacher assessments and parents' perceptions of benefits have reported improved self-organisation and confidence.

Although more traditional methods clearly prevail, the interest in Montessori suggests that SETs are seeking alternative ways of helping preschool children with ID to progress by increasing their engagement in learning.

\section{Discussion and Recommendations}

Differences in the extent to which a preschool environment is teacher-centred or child-centred reflect both individual schools and the society in which they operate. One study in Saudi Arabia found that children with learning difficulties in mainstream primary schools were perceived as normal, proposing that this corresponded with the social view that children who look normal and generally behave like other peers are accepted as normal (Al-Ahano, 2006). In the deeply conservative and conformist Saudi Arabian society, behaviours considered inappropriate limit the child's opportunities to participate in their community. Loving parents may therefore seek to improve those behaviours by any means for their child to benefit in later life. Behaviourist methods are readily compatible with the concern with correct behaviour as an aspect of moral education and compliance with social norms. However, behaviourism has been criticised for ignoring human emotions and limiting behaviours in a mechanistic way and, more seriously, it ignores the moral and ethical aspects of human identity (Hammond \& Wellington, 2012). This may be a concern for Saudi Arabia, because to the limits of their capacity, all Muslims in any situation should decide between good and less good courses of action. Overemphasis on a behaviourist approach may reduce some children's capacity to make such decisions. The plasticity of the brain in the early years mean that children's cognitive development should be supported as much as possible.

The pragmatic implementation of elements of Montessori suggests an evolution of educational thinking, away from an obviously medical model of diagnosing and reducing disability, and towards a recognition that supported independent learning is as important as teaching in the lifelong process to become and remain a good Muslim.

It is proposed that the IDC co-ordinator should build on the centre-home collaborative use of PECS by facilitating the exchange of best practice among SETs, in keeping with the importance attached to collaboration among professionals highlighted by Chen et al., (2009). It is further proposed that general and special education needs teachers of preschool children share a core programme of initial teacher education which offers a more constructivist approach, with specialisation to follow, in contrast to existing regulations (Ministry of Education, 2001) which separate them. SETs would have access to wider and richer choice of approaches and interventions which would shift the emphasis away from correcting deficits and towards development of the whole child, this fulfilling the Islamic goal of accepting difference in individuals who are equal as creations of Allah..

\section{Competing Interests Statement}

The author declares that there are no competing or potential conflicts of interest. 


\section{References}

Abdel Aziz, O. F., \& Alzarea, N. A. (2013). Effectiveness of a training program in developing teacher's knowledge in modifying the behavior of children with autism and mental retardation. Life Science Journal, 10(2), 2220-2229.

Al-Abdulkareem, R., \& Hentschke, G. C. (2014). Textbooks and constructivist pedagogy in Saudi Arabian school classrooms. Journal of Curriculum and Teaching, 3(2), 13-24. https://doi.org/10.5430/jct.v3n2p13

Al-Ahano, I. (2006). Representations of learning disabilities in Saudi Arabian elementary schools: A grounded theory study (Unpublished doctoral dissertation). Madison, USA: University of Wisconsin-Madison.

Al-Ahmadi, N. A. (2009). Teachers' perspectives and attitudes towards integrating students with learning disabilities in regular Saudi public schools (Unpublished doctoral dissertation). Athens, USA: University of Ohio.

Alajmi, N. S. (2006). The Kingdom of Saudi Arabia: Administrators' and special education teachers' perceptions regarding the use of functional behaviour assessments for students with mental retardation (Unpublished doctoral dissertation). Madison, USA: University of Wisconsin-Madison.

Al-Attas, S. M. N. (1979). Aims and objectives of Islamic education. Jeddah, Saudi Arabia: King Abdul Aziz University/Hodder and Stoughton.

Al-Jadidi, N. A. A. (2012). The professional preparation, knowledge and beliefs of kindergarten teachers in Saudi Arabia (Unpublished doctoral dissertation). Exeter, England: University of Exeter.

Almalki, N. S. (2013). Professional development needs of early intervention providers of preschoolers with moderate and severe disabilities in Saudi Arabia (Unpublished doctoral dissertation). Muncie, USA: Ball State University.

Al-Othman, H., Gregory, E., Jesse, J., \& Khalil, A. (2015). Early literacy model in a Saudi Arabian preschool: implementation in a different cultural context. International Journal for Cross-Disciplinary Subjects in Education (IJCDSE), Special Issue, 5(2), 2511-2522. https://doi.org/10.20533/ijcdse.2042.6364.2015.0342

Alquraini, T. (2011). Special education in Saudi Arabia: Challenges, perspectives, future possibilities. International Journal of Special Education, 26(21), 1-10.

AlShahrani, M. M. (2014). Saudi educators' attitudes towards deaf and hard of hearing inclusive education in Jeddah, Saudi Arabia (Unpublished doctoral dissertation). Exeter, England: University of Exeter.

Barker, R. M., Akaba, S., Brady, N. C., \& Thiemann-Bourque, K. (2013). Support for AAC Use in Preschool, and Growth in Language Skills, for Young Children with Developmental Disabilities. Augmentative and Alternative Communication, 29(4), 334-346. https://doi.org/10.3109/07434618.2013.848933

Birbili, M. (2000). Translating from one language to another. Social Research Update, 31. Guildford, England: University of Surrey.

Bowlby, J. (1982). Attachment. New York: Basic Books.

Braiden, H. J., McDanie, B., McCrudden, E., Janes, M., \& Crozier, B. (2012). A practice-based evaluation of Barnardo's Forward Steps early intervention programme for children diagnosed with autism. Child Care in Practice, 18(3), 227-242. https://doi.org/10.1080/13575279.2012.683773

Bronfenbrenner, U. (1979). The ecology of human development: Experiments by nature and design. Cambridge, MA: Harvard University Press.

Cairo Declaration on Human Rights in Islam (1990). Retrieved from http://www.fmreview.org/sites/fmr/files/FMRdownloads/en/FMRpdfs/Human-Rights/cairo.pdf.

Chen, D., Klein, M. D., \& Minor, L. (2009). Interdisciplinary perspectives in early intervention professional development in multiple disabilities through distance education. Infants and Young Children, 22(2), 146-158. https://doi.org/10.1097/IYC.0b013e3181a030e 0

Denning, C. B., \& Stanton-Chapman, T. L. (2014). Effects of a social communication intervention on interactive play for young children with disabilities. Journal of Education and Human Development, 3(3), 131-148. https://doi.org/10.15640/jehd.v3n3a11

Frederickson, N., \& Cline, T. (2009). Special educational needs, inclusion and diversity: A textbook (2nd ed.). Buckingham: Open University Press. 
Frost, L. A., \& Bondy, A. S. (2002). The Picture Exchange Communication System training manual (2nd ed.). Newark, DE: Pyramid Educational Products, Inc.

Ganz, J. B., \& Flores, M. M. (2010). Supporting the play of preschoolers with autism spectrum disorders: Implementation of visual scripts. Young Exceptional Children, 13(2), 58-70. https://doi.org/10.1177/1096250609351795

Goddard, L., Davidson, P. M., Daly, J., \& Mackey, S. (2008). People with an intellectual disability in the discourse of chronic and complex conditions: an invisible group? Australian Health Review, 32(3), 405-414. https://doi.org/10.1071/AH080405

Goldstein, H., Schneider, N., \& Thiemann, K. (2007). Peer-mediated social communication intervention: when clinical expertise informs treatment development and evaluation. Topics in Language Disorders, 27(2), 182-199. https://doi.org/10.1097/01.TLD.0000269932.26504.a8

Gray, C. (2000). The new Social Story book; Illustrated edition. Arlington, TX: Future Horizons.

Guralnick, M. J. (2011). Why early intervention works: A systems perspective. Infants and Young Children, 24, 6-28. https://doi.org/10.1097/IYC.0b013e3182002cfe

Hammond, M. \& Wellington, J. (2012). Key concepts in social science research. London: Routledge.

Hassanein, E. E. A. (2015). Inclusion, disability and culture. Rotterdam: Sense Publishers. https://doi.org/10.1007/978-94-6209-923-4

Heflin, L. J., \& Simpson, R. (1998). Intervention for children and youth with autism: Prudent choices in a world of exaggerated claims and empty promises. Part II: Legal/policy analysis and recommendations for selecting interventions and treatments. Focus on Autism and Other Developmental Disabilities, 13, 212-220.

Hegarty, S. (1995). Review of the present situation in special needs education. Geneva: United Nations Educational, Scientific and Cultural Organization. Retrieved from http://unesdoc.unesco.org/images/0010/001026/102688E.pdf

Howlin, P., Gordon, R. K., Pasco, G., Wade, A., \& Charman, T. (2007). The effectiveness of Picture Exchange Communication System (PECS) training for teachers of children with autism: A pragmatic, group randomised controlled trial. Journal of Child Psychology and Psychiatry 48(5), 473-481. https://doi.org/10.1111/j.1469-7610.2006.01707.x

Individuals with Disabilities Education Act, 20 U.S.C. 1400. (2004).

Jafari, M. F. (1992). Counseling values and objectives: A comparison of Western and Islamic perspectives. The American Journal of Islamic Social Sciences, 1, 326-339.

Jordan, R., Jones, G., \& Murray, D. (1998). Educational interventions for children with autism: A literature review of recent and current research. Research Report No 77. Norwich: HMSO.

Kaiser, A. P., \& Roberts, M. Y. (2013). Parent-implemented enhanced milieu teaching with preschool children with intellectual disabilities. Journal of Speech, Language, and Hearing Research, 56(1), 295-309. https://doi.org/10.1044/1092-4388(2012/11-0231)

Lifter, K., Foster-Sanda, S., Arzamarski, C., Briesch, J., \& McClure, E. (2011). Overview of play, its uses and importance in early intervention/early childhood special education. Infants and Young Children, 24(3), 225-245. https://doi.org/10.1097/IYC.0b013e31821e995c

Lillard, A. S., \& Else-Quest, N. (2006). Evaluating Montessori education. Science, 313, 1893-1894. https://doi.org/10.1126/science.1132362

Lovaas, O. I. (1987). Behavioral treatment and normal education and intellectual functioning in young autistic children. Journal of Consulting and Clinical Psychology, 55, 3-9. https://doi.org/10.1037/0022-006X.55.1.3

Macdonald, S.J. (2009). Windows of reflection: Conceptualizing dyslexia using the social model of disability. Dyslexia, 15(4), 347-362. https://doi.org/10.1037/0022-006X.55.1.3

Machalicek, W., O’Reilly, M. F., Beretvas, N., Sigafoos, J., Lancioni, G., Sorrells, A., ... \& Rispoli, M. (2008). A review of school-based instructional interventions for students with autism spectrum disorders. Research in Autism Spectrum Disorders, 2(3), 395-416. https://doi.org/10.1016/j.rasd.2007.07.001

May-Benson, T. A., \& Koomar, J. A. (2010). Systematic review of the research evidence examining the effectiveness of interventions using a sensory integrative approach for children. American Journal of 
Occupational Therapy, 64(3), 403-414. https://doi.org/10.5014/ajot.2010.09071

McLachlan, R., Gilfillan, G., \& Gordon, J. (2013). Deep and persistent disadvantage in Australia. Productivity Commission staff working paper. Canberra: Productivity Commission. Retrieved from http://www.pc.gov.au/research/completed/deep-persistent-disadvantage ISBN 978-1-74037-445-3

Meyer, L. H., \& Evans, I. M. (2006). Literature review on intervention with challenging behaviour in children and youth with developmental disabilities. NZ, Wellington: University of Wellington College of Education. Retrieved from https://www.educationcounts.govt.nz/publications/special_education/15183.

Ministry of Education. (1976). Educational policy: Government decree 89/A/23/03/76.(MOE). Riyadh, Saudi Arabia: Ministry of Education.

Ministry of Education. (2001). Regulations of Special Education Programs and Institutes. Riyadh, Saudi Arabia: Ministry of Education.

Ministry of Education. (2012). Educational policy in the Kingdom of Saudi Arabia. Riyadh, Saudi Arabia: Ministry of Education.

National Research Council. (2000). Assessment in early childhood education. In Eager to learn: Educating our preschoolers. Washington, DC: The National Academies, pp.233-260.

Open University, Department for Children, Schools and Families, Royal Holloway University of London, \& NSPCC (2007). The developing world of the child: Resource pack. Leicester: NSPCC.

Panerai, S., Ferrante, L., \& Zingale, M. (2002). Benefits of the Treatment and Education of Autistic and Communication Handicapped Children (TEACCH) programme as compared with a non-specific approach. $\begin{array}{lllll}\text { Journal of Intellectual Disability Research, } & 46(4), & 318-327 .\end{array}$ https://doi.org/10.1046/j.1365-2788.2002.00388.x

Patai, R. (2002). The Arab mind. Long Island City, New York: Hatherleigh Press.

Räty, L., Kontu, E. K., \& Pirttimaa, R. (2016). Teaching children with intellectual disabilities: Analysis of research-based recommendations. Journal of Education and Learning, 5(2), 318-336. doi:10.5539/jel.v5n2p318 https://doi.org/10.5539/jel.v5n2p318

Richards, S. B. (2014). Cognitive and intellectual disabilities: Historical perspectives, current practices, and future directions. New York: Routledge.

Risha, S. (2014). Education and curricular perspectives in the Qur'an. London: Lexington Books.

Rogers, S. J. (2000). Interventions that facilitate socialization in children with autism. Journal of Autism and Developmental Disorders, 30(5), 399-409. https://doi.org/10.1023/A:1005543321840

Samadi, H., \& Marwa, N. (2006). A teacher's guidelines, for a kindergarten curriculum. Saudi Arabia: Ministry of Education. (Document in Arabic Language).

Sammons, P., Sylva, K., Melhuish, E. C., Siraj-Blatchford, I., Taggart, B., \& Elliot, K. (2003). The Effective Provision of Pre-School Education (EPPE) project: Technical paper $8 b$ - measuring the impact of pre-school on children's social/behavioural development over the pre-school period. London: DfES / Institute of Education, University of London.

Saracho, O. N. (2012). An integrated play-based curriculum for young children. Abingdon: Routledge.

Schalock, R. L., Borthwick-Duffy, S. A., Bradley, V., Buntinx, W. H. E., Coulter, D. L., Craig, E. M. ... \& Yeager, M. H. (2010). Intellectual disability: Definition, classification, and systems of supports (11th ed.). Washington DC: AAIDD.

Schlosser, R., \& Wendt, O. (2008). Effects of augmentative and alternative communication intervention on speech production in children with autism: A systematic review. American Journal of Speech-Language Pathology, 17(3), 212-230. https://doi.org/10.1044/1058-0360(2008/021)

Schopler E, Mesibov G and Hearsey K (1995). Structured teaching in the TEACCH system, In E. Schopler, \& G. B. Mesibov (Eds.), Learning and cognition in autism (pp. 243-267). New York: Kluwer Academic/Plenum. https://doi.org/10.1007/978-1-4899-1286-2_13

Scourfield, J., Gilliat-Ray, S., Khan, A., \& Otri, S. (2013). Muslim childhood: Religious nurture in a European context. Oxford: Oxford University Press. https://doi.org/10.1093/acprof:oso/9780199600311.001.0001

Shevell, M. (2008). Global developmental delay and mental retardation or intellectual disability: conceptualization, 
evaluation, and etiology. Pediatric Clinics of North America, 55(5), 1071-1084. https://doi.org/10.1016/j.pcl.2008.07.010

Shklarov, S. (2007). Double vision uncertainty: The bilingual researcher and the ethics of crosslanguage research. Qualitative Health Research, 17, 529-538. https://doi.org/10.1177/1049732306298263

Siraj-Blatchford, I., \& Clarke, P. (2001). Diversity and the curriculum. In I. Siraj-Blatchford, \& P. Clarke (Eds.), Supporting identity, diversity and language in the early years (pp. 66-89). Buckingham: Open University Press.

Smith, T. (2001). Discrete trial training in the treatment of autism. Focus on Autism and Other Developmental Disabilities, 16, 86-92. https://doi.org/10.1177/108835760101600204

Virues-Ortega, J., Julio, F. M., \& Pastor-Barriuso, R. (2013). The TEACCH program for children and adults with autism: A meta-analysis of intervention studies. Clinical Psychology Review, 33(8), 940-953. https://doi.org/10.1016/j.cpr.2013.07.005

Wasik, B. (2008). When fewer is more: small groups in early childhood classrooms. Early Childhood Education Journal, 35(6), 515-521. https://doi.org/10.1007/s10643-008-0245-4

World Health Organization. (2007). Early childhood development: a powerful equalizer. Geneva: World Health Organization. Retrieved from http://www.who.int/social_determinants/resources/ecd_kn_report_07_ 2007.pdf.

World Health Organization with UNICEF (2012) Early Childhood Development and Disability: A discussion paper. Malta: World Health Organization. Retrieved from http://apps.who.int/iris/bitstream/10665/75355/1/9789241504065_eng.pdf

Wilkinson, K. M., \& Hennig, S. (2007). The state of research and practice in augmentative and alternative communication for children with developmental/intellectual disabilities. Mental Retardation and Developmental Disabilities Research Reviews, 13(1), 58-69. https://doi.org/10.1002/mrdd.20133

Worthington, E. M. (2008). Effective learning environments in preschools. (Unpublished master's dissertation), Ames, USA: Iowa State University.

Yadav, A. K. (2016). Social work and inclusive education for children with special needs. International Journal of Advanced Research, 4(12), 1347-1351. https://doi.org/10.21474/IJAR01/2528

Zanolli, K., Daggett, J., \& Adams, T. (1996). Teaching autistic children to make spontaneous initiations to peers using priming. Journal of Autism and Developmental Disorders, 2, 407-422. https://doi.org/10.1007/BF02172826

\section{Copyrights}

Copyright for this article is retained by the author(s), with first publication rights granted to the journal.

This is an open-access article distributed under the terms and conditions of the Creative Commons Attribution license (http://creativecommons.org/licenses/by/4.0/). 